\title{
La ciudad letrada en sus diagonales: una lectura descentrada de dos poemas de sor Juana
}

\author{
The Lettered City in its Diagonals: \\ an Off-Center Reading of Two Poems by Sor Juana
}

\section{Carla Anabella Fumagalli*}

Resumen: El libro de Ángel Rama La ciudad letrada, de 1984, ha suscitado desde su publicación incontables artículos y ensayos. En él, el crítico estudia el modo en que los letrados latinoamericanos se vinculan con las esferas de poder y, a partir de ello, propone una cartografía de las ciudades latinoamericanas. En este trabajo abordaremos la forma en que la poesía de sor Juana Inés de la Cruz es tratada por el crítico uruguayo en su libro y analizaremos este tratamiento en función de las representaciones de los vínculos con el poder en la dedicatoria a la virreina y el prólogo al lector de 1689 y 1690 , respectivamente.

Palabras Clave: Ciudad letrada; Sor Juana Inés de la Cruz; Legitimación; Paratexto.

ABSTRACT: Angel Rama's book, La ciudad letrada of 1984 has brought forward numerous articles and essays since its publication. In it, the critic proposes a way in which Latin American letrados relate to the circles of power, and through it, a cartography of Latin American cities. In this article we will approach the manner in which sor Juana Inés de la Cruz's poetry is treated by the Uruguayan in his book and analyze it according to the representation of bonds with the circles of power in the dedication to the vicereine and the prologue for the reader from 1689 and 1690 respectively.

KEY wORDS: Lettered City; Sor Juana Inés de la Cruz; Legitimation; Paratexte.

Recibido: 23 de marzo de 2018

Aceptado: 22 de agosto de 2018

* Universidad de Buenos Aires, ConicET (carlaafumagalli@gmail.com). 
Ya la ciudad, que vecina fue al cielo, con tanto arder sólo guarda de su ser vestigios, en su rüina.

Sor Juana Inés de la Cruz, "Alma que al fin se rinde al amor resistido: es alegoría de la ruina de Troya"

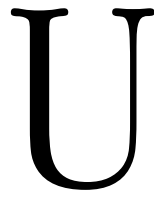

na tendencia muy visible en la crítica de la literatura latinoamericana, quizás de la última década, rinde liviano homenaje a Ángel Rama mencionando, casi automáticamente y como quien paga un peaje obligatorio, La ciudad letrada (1984) cada vez que sus hipótesis y lecturas se acercan al terreno de la relación entre escritura y poder. De este modo, el título del ensayo de Rama parece condensar ciertas ideas sobre la escritura en América Latina que aparentan ser unívocas y estar ya clausuradas. Escribir en este continente, si invocamos como una plegaria vacía el nombre del uruguayo, parece ser el equivalente a la relación con un poder estatal o económico de dependencia que se explica a sí misma y que, por lo tanto, ya está caduca.

Este texto pretende hacer una lectura del ensayo de Ángel Rama que explore los motivos que habilitan ese peaje obligado, al mismo tiempo que dan lugar a números de revistas, libros, capítulos y artículos de críticos que leen y releen, arman y desarman las hipótesis, mapas y series que propone el libro. Al mismo tiempo, revelaremos el lugar que Rama le da a sor Juana Inés de la Cruz en su libro y analizaremos cómo se corresponde ese espacio con la cartografía de su poesía, especialmente en la dedicatoria a la virreina y el prólogo al lector de 1689 y 1690, respectivamente. En estos textos, evidenciaremos la posición múltiple que sor Juana ocupa en la ciudad letrada, que, a su vez, habilita germinalmente el ensayo del crítico uruguayo. Como comenta Álvaro Fernández Bravo (2006: 186), el libro de Rama es un manuscrito inconcluso que debe leerse como tal. Sus capítulos mejor argumentados y sólidos son los primeros tres, mientras que los últimos tienen las marcas de una obra en proceso. Tomaremos 
entonces, también porque es nuestro punto de interés, los tres primeros especialmente.

\section{EL ORDEN Y LOS PASAJES}

La ciudad letrada (1984) de Ángel Rama es un libro póstumo e inconcluso, cuya primera versión fue una conferencia dictada en la Universidad de Harvard en octubre de 1980 bajo el título "Funcionamiento del sistema literario en América Latina”. En 1982, se convirtió en un trabajo para un simposio sobre urbanización en Stanford, organizado por Richard Morse. Pocos días antes de su muerte, Rama envía "La ciudad ordenada" a la Revista de la Universidad de México, que lo publica en enero de 1983 con algunas imágenes y mapas que no aparecerán en el libro póstumo. Las actas del simposio, incluyendo el primigenio ensayo de 26 páginas, "La ciudad letrada", fueron publicadas por el Consejo Latinoamericano de Ciencias Sociales, en 1985. Tanto en el libro póstumo y la revista como en el simposio, Rama despliega muchas de las tesis que la crítica latinoamericana continúa desarrollando en la actualidad. Me refiero principalmente a la relación entre los intelectuales, el poder, la circulación del conocimiento y su vínculo con el público en América Latina.

En el inicio, dice Rama, hay una separación entre la cosa y su signo; entre la ciudad real y la ciudad imaginada. Las formas sociales, sus integrantes e instituciones, se superponen a los modelos de una ciudad aún inexistente. Su signo remite a la nada, o, mejor dicho, remite a un orden (palabra que Rama distingue), a una "forma distributiva" (1998: 19). El concepto mismo de "ciudad barroca" emerge de la confrontación de dos formas inmateriales: la forma distributiva en damero de una urbe imaginaria, y una "edad barroca" (1998: 8). Esa conjugación entre forma y abstracción crea un orden simbólico que el crítico describirá en tanto establece también una jerarquía de los poderes y las instituciones coloniales. Leerá, en el espacio imaginado, las interrelaciones concretas entre, por ejemplo, letrados y mecenas. 
La estrategia semiológica de Rama se evidencia en las primeras páginas de su libro: en su ambición por "explicar" la sociedad latinoamericana en su singularidad; debe primero demostrar la no-referencialidad (o la referencialidad mediada) del signo en el Barroco (vía el Foucault de Las palabras y las cosas [1966] 2002) para justificar el carácter imaginario o ideal de la ciudad barroca, ese espacio-tiempo privilegiado en el que lee la condensación de ciertos vínculos, procedimientos y estrategias que caracterizan el modo en que los letrados latinoamericanos ocupan posiciones de poder. A su vez, ese nuevo signo, "ciudad barroca" encontrará un referente más preciso de la realidad americana en la Ciudad de México, si seguimos las hipótesis de Beatriz Colombi que sugieren que es el caso testigo del ensayo (2006: 5). La ciudad del Nuevo Mundo, entonces, representará una morfología no de actividades (mercantiles, de ocio, profesionales, etc.) sino de estatus determinados y es, en el ensayo de Rama, tanto el archivo de una jerarquía como su modo de operar.

Como Derrida propone en De la gramatología, en todo par supuestamente equilibrado yace la predominancia de alguno de sus componentes. Para ilustrarlo, toma la lingüística y la constitución del signo saussuriano. ${ }^{1}$ Rama hace también de esta operación parte de su estrategia semiológica en el par signo-referente, donde prevalece el elemento mental por sobre el material. La forma social predomina sobre la forma espacial del damero, una forma urbana como cualquier otra, dice Rama, porque no determina en sí misma la jerarquía y el orden, sino que ese proceso se constituye en el archivo (quizás aquel que Sigüenza y Góngora salva del incendio, en Alboroto y motín de los indios de México) en que el orden institucional se

1 "Un discurso declarado confirma, diciendo lo que se sobreentiende sin ser dicho, la subordinación de la gramatología, la reducción histórico-metafísica de la escritura al rango de instrumento sometido a un lenguaje pleno y originariamente hablado" (Derrida 1986: 40). El vínculo con las tesis derrideanas no termina en la deconstrucción, sino que todo el ensayo de Rama descansa sobre la hipótesis de que es la escritura y no la oralidad la que es el centro del conocimiento, y, por lo tanto, la aliada del poder. Así como Derrida propone que la lingüística saussuriana se equivoca al postular que la lengua oral precede a la escritura, Rama adhiere al precepto de que "en la historia cultural latinoamericana [...] no habría logocentrismo sino grafocentrismo" (Aguilar 2006: 232). 
asienta y donde podemos leer las huellas que esa institucionalización y ordenamiento dejaron en los planos de las ciudades.

La forma del damero fue elegida por el Imperio español para la construcción de ciudades en América por la conveniencia de su potencial crecimiento ya que supone un proyecto de constante expansión y sin clausura. La disposición ortogonal de sus manzanas propone un trazado al infinito, que mantiene en el centro la Iglesia y las casas de la realeza. En las ordenanzas de Felipe II del 13 de julio de 1573, se intenta, con mucho detalle, regularizar la construcción de ciudades en América; una de sus disposiciones (la ordenanza 26, párrafo 127), mandaba que "En la plaza no se den solares particulares; dense para fábrica de la Iglesia y Casas Reales" (Solano 1996: 213). El damero responde también a la racionalización y sistematización, principios barrocos por excelencia, que obliteran toda particularidad local y real. De este modo, la retícula ortogonal trazada por Alonso García Braco y supervisada por el propio Cortés sirve de modelo para imaginar la ciudad que Rama tenía en mente mientras articulaba planes y planos con la realidad americana. Literalmente, sus edificios, solares, calles y canales fueron resignificados por Cortés. Muchas veces ese procedimiento implicaba la total o parcial destrucción de lo que antes ocupaba su lugar.

Siguiendo las huellas, cenizas y ruinas que quedaran de la vieja Tenochtitlan, el alarife [García Bravo] fue diseñando el nuevo plano a partir del centro que ocupara el Templo Mayor y la residencia de Moctezuma, lugares que renacerán como plaza, con la sede del nuevo poder, la casa del cabildo y la nueva residencia de Cortés, [...]. A partir de la plaza se trazaban las calles paralelas y perpendiculares y se parcelaban los terrenos. [... ] Así, el centro se fue conformando por las residencias de los ciudadanos más ricos, los capitanes de Cortés en primer lugar, y un poco más alejados, otros conquistadores menos poderosos (Rodilla 2014: 60).

La periferia de esta nueva ciudad estaba ocupada por los indios, aunque su separación no era tajante. Las cédulas reales demuestran una gran movilidad de españoles en los barrios de los indios y viceversa (Rodilla 2014: 55) ya que, en ellas, se solicitaba que la división entre ambos fuera 
más consistente. Esta periferia será, en el ensayo de Ángel Rama, el tercer anillo que rodea la ciudad escrituraria, el del campo indígena. Entre ambos (es decir, entre la plaza o centro de poder y el campo indígena) surge, según Rama, pero también de acuerdo a la historia urbana de la ciudad de México, un anillo que él llama "anillo urbano" (1998: 45) compuesto por la "plebe, tan en extremo plebe" descrita por Carlos de Sigüenza y Góngora en Alboroto y motín de los indios de México (1984: 113). En La ciudad letrada pareciera que los anillos concéntricos limitan con tajante seguridad la violación de esas fronteras imaginarias, como si el trazado de la ciudad ideal incluyera murallas infranqueables, lo que habilita la crítica que tantos autores le han hecho: la ausencia de movilidad. ${ }^{2}$ Es cierto, Rama sostiene un análisis geográfico y lingüístico en el que la lengua española delimita los espacios, pero, al mismo tiempo, permite el pasaje entre unos y otros (de personas, de textos, de lenguas). El texto de Rama está basado en un estudio semiológico y todo el libro se propone develar los signos detrás de los signos, una operación sin dudas lingüística, en la que la elección entre lo real y lo ideal es muy clara. Así, en el privilegio del análisis simbólico que se ve favorecido en el ensayo, se puede entrever que la división entre anillos no es tan absoluta, sino que habilita y recoge las críticas posteriores.

Tanto la ciudad como el poder son representados primero en papel y luego en la realidad. Virreyes, clérigos, encomenderos, inquisidores nacen en letra y luego se materializan, ya que, para existir, primero deben soñarse y planearse. La escritura actúa de este modo como condición de posibilidad de la realidad y ese lugar de preeminencia es el que, según Rama, la escritura ocupa en y da presencia a, la ciudad letrada. La preferencia de la escritura por sobre la oralidad es una crítica constante a las tesis del libro. Pienso en John Beverly y Rolena Adorno, por ejemplo, para quienes la oralidad representa la subalternidad de la que Rama parece hacer caso

2 Volviendo a Alboroto y motín... de Sigüenza y Góngora, la circulación de sujetos subalternos representados, no sólo por el motín en sí, sino por las constantes murmuraciones que permean a lo largo del texto (Zanetti 2000: 395), para fijarse en la carta del letrado que ofrece una versión "oficial" de los hechos, obstaculiza las nociones de centro y periferia y de anillo cerrado. 
omiso, como si no existiera una alternativa a la producción dentro de los anillos de la ciudad letrada. ${ }^{3}$ Rama no parte del mismo lugar que Tzvetan Todorov en La conquista de América, por ejemplo, quien también hace uso del binomio oralidad-escritura para comprender el espacio americano de la Conquista. Todorov sugiere que la Conquista del continente significó un éxito para los españoles por su dominio de la escritura, y por lo tanto de los signos, mientras que, de acuerdo con las tesis de Ángel Rama, la superioridad de la escritura se vincula con su poder para fijar una idea que luego se convertirá en realidad: "El plano ha sido desde siempre el mejor ejemplo de modelo cultural operativo. Tras su aparencial registro neutro de lo real, inserta el marco ideológico que valora y organiza esa realidad y autoriza toda suerte de operaciones intelectuales a partir de sus proposiciones, propias del modelo reducido" (1998: 22).

Sin embargo, señala Rama, hay algo en el plano que debe quedar excluido. Un plano cualquiera traza los límites entre el adentro y el afuera, la frontera entre lo que se traza y lo que no, excepto el damero que, por su potencialidad infinita, no tiene límites concretos, sino eternamente provisorios. La ciudad que se traza no tiene fronteras, ni una periferia establecida y Rama extrapola esta característica a la relación entre el centro madrileño, sus colonias y otras ciudades europeas. La dependencia y el abastecimiento económico y cultural americano se reproducen en la relación entre Madrid y Sevilla y otros centros europeos, como Génova y Ámsterdam. Los límites de la ciudad americana están, entonces, cada vez más lejos.

No podemos olvidar, como señala Gonzalo Aguilar, que Rama comienza su ensayo pensando en dos extremos de su arco temporal y espacial: de Tenochtitlan a Brasilia (2006: 173). Ambas ciudades representan la racionalidad y el planeamiento urbano por excelencia. Según Aguilar, el exilio de Rama —su situación diaspórica o similar a un Heimatlos— es lo

3 Rolena Adorno publica en 1987 "La ciudad letrada y los estudios coloniales", y John Beverly publica en 1999 un capítulo titulado "The 'Lettered City' and the Tupac Amaru Rebellion" en su libro Subalternity and Representation. Ambos críticos sostienen que numerosos textos indígenas y mestizos ubicados en los bordes de su "ciudad letrada" habían sido ignorados por Rama. 
que vuelve homogéneo (o panorámico) su objeto de estudio: la cultura latinoamericana (174). Tanto Tenochtitlan como Brasilia (o la ciudad-damero por excelencia, La Plata) están atravesadas por avenidas que dividen y comunican el territorio de norte a sur y de este a oeste. Brasilia y Tenochtitlan (y no La Plata, que sí cuenta con diagonales que proporcionalmente dividen manzanas y luego barrios) tienen también calles curvas: mientras Brasilia está organizada en dos arcos, como las alas de un pájaro o un avión, Tenochtitlan se organiza en torno a la antigua y circular ciudad mexica, que obliga al plano a adaptarse. Ambas ciudades se convierten en signos aprehensibles en su totalidad, cuando se las mira desde arriba. El ave que forma la capital brasileña sólo puede ser percibida desde el cielo, o en el plano. La antigua ciudad de Tenochtitlan se encuentra en las excavaciones arqueológicas en la ciudad y en los antiguos mapas y tampoco puede ser percibida a simple vista.

Pensar la ciudad es ordenar la estructura social bajo una forma. El damero tiene una particularidad material que propicia los pasajes de sujetos y, para consolidar nuestra hipótesis, de ideas. La forma ortogonal ilustra, de algún modo, el mismo ensayo de Rama. Su centro, la ciudad letrada, y sus diagonales - la escrituraria, pero también la ordenada, la moderna, la politizada y la revolucionada (títulos de los demás capítulos del libro) - conforman un plano en damero que justifica e ilumina la visión panorámica que tiene el ensayo de la historia latinoamericana y su solo aparente inmovilidad temporal y conceptual. Esas diagonales también favorecen los aires renovadores que la crítica da constantemente al ensayo y esas menciones vacías que, siempre entre paréntesis (Rama, 1984), se diseminan en monografías, artículos y ponencias que descentran la ciudad letrada y evidencian la potencialidad del concepto por fuera de la dinámica centro-periferia.

El afán genealógico y superador de los límites temporales que Ángel Rama muestra en su ensayo pretende echar luz sobre las relaciones entre un grupo particular de sujetos y el poder. Lo que está detrás de este supuesto, además de la lectura de De la Conquista a la Independencia de Mariano Picón Salas, es la idea de ver en los criollos del xIX y en los inte- 
lectuales contemporáneos las marcas de un tipo de vínculo que floreció durante la Colonia. ${ }^{4}$ Sin embargo, la atemporalidad del ensayo de Rama no es tan radical, ya que aun cuando se sirve de un concepto transhistórico, esto no significa que sea inmutable. Por el contrario, una de las preocupaciones del crítico es identificar y revisar las mutaciones de la ciudad letrada a lo largo de la historia. Hay, aun así, un contraargumento clave y es que ciertos aspectos de la ciudad letrada son, necesariamente, inmutables, si no, no podría conceptualizarse. Los aspectos inmutables son dos: la urbanidad y la escritura.

Las críticas que recibió el ensayo se basaron también en esta paradoja, ya que cuestionan el uso invariable del concepto de letrado a lo largo de cinco siglos, además de la minimización de otras prácticas discursivas ajenas al poder que constituyen una alternativa a esa circulación del conocimiento y abren la posibilidad de invectivas o ataques al poder hegemónico. Algunos autores como Mabel Moraña (1995 y 1997) o Julio Ramos ([1989] 2003) señalan la ausencia de un manejo del detalle histórico que provoca la inmutabilidad del contexto - siempre urbano- en el que se da la receta para el vínculo entre la escritura y el poder. En segundo lugar, el silenciamiento de otros discursos - orales, disidentes- ignora otro tipo de relación con el poder que no pasa por la escritura, ni por la ciudad. Como explicamos antes, Rolena Adorno es quien más amplía la idea de ciudad letrada sin condenarla, ya que mueve el centro del ensayo de la relación poder-escritura para concentrarse en las posibilidades del subalterno ante esta dinámica y evidencia algunos usos disidentes de la letra como estrategia discursiva.

4 Nos referimos al consabido contexto de escritura y publicación de La ciudad letrada, dedicado a los intelectuales y a las organizaciones que apoyaron a Rama durante su contienda con el gobierno norteamericano el cual, en 1983, le había negado la visa de residencia por su participación en Marcha, por haber dirigido la Biblioteca Ayacucho (que, según Estados Unidos, editaba autores comunistas), y por la presentación de la obra de Rubén Darío, "acto subversivo". 
LOS PASAJES DE SOR JUANA

Para poder ver con mayor claridad estos pasajes y diagonales que propone La ciudad letrada, propongo una lectura descentrada de dos poemas de sor Juana Inés de la Cruz: la dedicatoria a la virreina y el prólogo al lector, de 1689 y 1690, respectivamente.

En el ensayo de Rama, sor Juana sólo aparece (en un párrafo) como uno de los dos intelectuales que en 1680 participaron del recibimiento del Virrey con los Arcos Triunfales, textos que, según el crítico, ejemplifican el "uso político del mensaje artístico [que] fue extraordinariamente frecuente en la Colonia" (1998: 37). Por otro lado, los Arcos, en tanto textos escritos, pero también y principalmente representados, configuran el discurso barroco privilegiado de la ciudad letrada ya que componen un sistema simbólico independiente que otorga significado a la realidad. La singularidad sorjuanina, de acuerdo con el ensayo de Rama, descansa en haber enfocado su poética en la desconexión entre un sistema de signos referencial, como el de los afectos, y el discurso literario. Esta desconexión es lo que Rama encuentra más "letrado" en sor Juana, ya que su condición de monja no la ubica consistentemente en el círculo de educadores ni de la plebe ni de los gobernantes, que él describe como letrados. Escribe Rama: "la operación original (y genial) de sor Juana consiste en haber hecho de esa desconexión entre el discurso literario y la urdimbre de los afectos, el tema central de su poética" (38).

Sin embargo, el mismo Arco Triunfal que Ángel Rama aprovecha para evidenciar las redes de poder colonial entre poderosos y letrados tiene también su costado subalterno. No sólo participaban en el espectáculo sor Juana Inés, Carlos de Sigüenza y Góngora, o la clase noble, sino que, además, otros sectores de la ciudad por fuera del anillo letrado formaban también parte de él. Algunos de ellos eran los indios y mestizos en las corridas de toros, una parte de la celebración por la llegada de los nuevos virreyes. En palabras de Judith Farré: "El pasatiempo taurino con el que las clases populares acaparan puntualmente el protagonismo de la fiesta forma parte de una risa entendida como patrimonio popular, que permite 
percibir la realidad celebrativa desde una perspectiva jocosa" (2006: 81) y "transforma a los principales actores del poder político y económico en ocasionales testigos de otras vías de exhibición festiva, en la que los protagonistas, invirtiendo sus papeles, pasan a ser los últimos sectores de la pirámide social y donde los valores que necesariamente imperan son los de la cultura y la fiesta popular" (80). De este modo, la fiesta es un espectáculo público donde cada clase desempeña un papel, incluso las subalternas. Además, como apunta Beatriz Mariscal Hay, en la misma Explicación del Arco, sor Juana es consciente de que su mensaje debía llegar a un público diverso: "por un lado a 'los entendidos' y por otro a 'los vulgares'; los primeros podrían descifrar las inscripciones y establecer las relaciones por analogía entre las figuras mitológicas y el homenajeado, mientras que serían 'los colores' los que atraerían los ojos de los segundos" (1993: 93). Esta participación de otros sectores externos al anillo letrado otorga al ejemplo de Rama, que a primera vista parecía absoluto y evidente, el matiz de relatividad que la crítica reclama. De este modo, cuando el uruguayo define el discurso barroco y escribe: "Su mejor exposición no está en los textos literarios y mudos que hemos conservado, sino en la fiesta que ellos significaban, por lo cual su expresión más ilustrativa son los arcos triunfales con que se conmemoraban los grandes acontecimientos" (1998: 38), construye una de las diagonales que trazábamos al comienzo del trabajo, y otorga a la lectura atenta la posibilidad de interponer los espacios, individuos y oportunidades de la subalternidad -con sus condiciones de posibilidad- entre las palabras que los olvidaron.

La astucia de Rama está en citar el Neptuno alegórico como el mejor ejemplo de la articulación entre letrados y el poder debido a la laudatio del nuevo gobernante que auspicia una relación de intercambios. Es una astucia crítica, ya que ubica a sor Juana en el centro de la atención política en 1680, pero además proyecta la operación simbólica propuesta para el Arco, al resto de su poesía, aun cuando ésta coloque a la poeta en otras zonas de la ciudad letrada, permeables más a discutir con el poder - o, por lo menos, con cierto poder, pienso en la Respuesta a sor Filotea y la Carta de Monterrey - que a protegerlo: como escritora, pero no educadora; 
como artista de la corte, pero monja de clausura; como monja de clausura, pero acreedora de grandes sumas de dinero, tierras y cargos dentro del convento. La idea de que el discurso literario de la poesía de sor Juana no alude a un sistema referencial recuerda a otro libro de la década de los ochenta, Sor Juana Inés de la Cruz o las trampas de la fe, de Octavio Paz. Allí, Paz sugiere, de un modo inverso al de Rama, que sor Juana no necesita la prueba del amor para escribir sobre él, cuando analiza "Detente, sombra de mi bien esquivo", sino que son las fantasías de un amor - cualquiera - las que pueblan sus horas (1992: 381). Ambos, Paz y Rama, ven en sor Juana una escritora que no escribe acerca de una realidad concreta, sino que la explica. Sin embargo, mientras Rama concibe una operación a contrapelo de la ciudad letrada - pero desde ella - cuando sostiene esta desconexión o, mejor dicho, un sistema de signos independiente que "como una red se ajusta sobre la realidad para otorgarle significación; por momentos se diría que hasta simple existencia" (1998: 38), Paz no la tolera y necesita darle un referente aunque no sea más que fantasioso. Este tipo de análisis que intentan divorciar vida y obra o discurso y referencia -así como aquellos que hermanan irreflexivamente ambas zonas- obliteran la posibilidad de considerar la poesía de sor Juana como el espacio donde encontrar una autora estratega, consciente de su posición, además de leer esa poética en otros textos ya menos políticos, ya menos ligados a los afectos. $^{5}$

De hecho, si leyéramos sólo un divorcio entre sistemas de sentido - simbólico y referencial- en la poesía sorjuanina, ignoraríamos una cartografía de los vínculos que la misma ciudad letrada plantea, y no me refiero a la poesía amorosa ni de corte, ya que ambas proponen otro sistema referencial. La primera supone un problema en tanto se sugiera una

Facundo Ruiz, en el prólogo a la antología Nocturna, mas no funesta. Poesía y cartas de sor Juana (Buenos Aires: Corregidor), aborda esta independencia de sistemas y lo llama la geometría de los afectos: "Hay, efectivamente, en la poética de sor Juana una geometría de los afectos [...]. Y eso que da a pensar en la obra de sor Juana es el deseo (esencia del hombre y la mujer en igual medida), esa inclinación más o menos negra que determina a hacer algo y a conservarse en igual medida (esencialmente), esa forma del afecto y de ese vínculo: el amor, su geometría (2014: 56-57). 
identificación entre autora y yo lírico, mientras que la segunda se supone casi enteramente referencial. ${ }^{6}$ De este modo, propongo un análisis del diálogo entre el soneto-dedicatoria "El hijo que la esclava ha concebido" y el prólogo en verso "Esos versos lector mío" que ilustra la ambivalencia entre los conceptos de autoría y autoridad, como una alternativa a la desconexión entre un sistema referencial y el discurso literario entendido por Rama como la poética sorjuanina. Si bien esa desconexión podría verse en el Arco Triunfal en tanto el texto "explica" la realidad, la dedicatoria y el prólogo presentan una alternativa ya que ellos también, en su naturaleza paratextual, explican "otra" realidad: el vínculo con la mecenas a quien se dedica la producción y el libro al que antecede, sin desconectarse completamente del centro de la ciudad letrada, pero tampoco en dependencia exclusiva de él para tener u otorgar sentido.

El soneto que Alfonso Méndez Plancarte numeró como el 195 funcionó, en Inundación castálida, como la dedicatoria que la poeta hizo a su mecenas. El epígrafe que lo acompaña anticipa el tipo textual del soneto, una dedicatoria, y lo contextualiza. El texto sugiere un vínculo entre mecenas, obra y autora que descansa sobre dos disciplinas: el derecho y la biología. Así, la obra de sor Juana es tratada como "el hijo", "opimo fruto", "borrones", "hijos del alma", "partos del pecho" y "conceptos" que, aun manu propria sorjuanina, son propiedad por derecho de la mecenas. El motivo de la obra como parto que pertenece a quien la publica es un eco de la dedicatoria de Lope de Vega al Conde Duque de Olivares en La Circe con otras rimas y prosas, de 1623. El texto en prosa del Fénix nombra su obra como "hijos de quien no puede ampararlos" y "esclavos nacidos en su ilustrísima casa, los que no pudieron serlo por sangre, serán Guzmanes por crianza" (s/n). El derecho, en ambas dedicatorias, regula la biología y las metáforas relativas al parto y coloca a los autores frente al mecenas en situación de ofrenda, pero también de reordenamiento de los papeles. Las

6 Más sobre los problemas que supone la poesía amorosa de sor Juana en Alatorre 2003; Buxó 1995: 85-100; Egido 1987: 79-183; Fort 1991: 33-45; Glantz 1995; Zavala 1980: 367-403, y Sabat de Rivers 1995. Sobre la poesía cortesana o de situación, véase: Méndez 2016: 37-52; Poot Herrera 2016: 17-35; Navascués 2010: 123-138. 
dedicatorias salvaguardan el lugar del mecenas, quien, aun cuando fija su nombre en la portada, se consolida en la dedicatoria como verdadero/a dueño/a de los textos. Los poemas se refieren a la propiedad de la obra, que afecta directamente la autoría y consolida una estrategia de legitimación autoral sostenida en la presunción de, justamente, no asumir la responsabilidad por lo escrito.

El epígrafe de la dedicatoria sorjuanina se hace eco de esta estrategia y propone también una narración de la inocencia sorjuanina que se repite en otras zonas de su obra a partir del motivo del "descuido de la obra" cuando se refiere a los papeles "que su Excelencia la pidió y pudo recoger Sóror Juana de muchas manos, que no estaban menos divididos que escondidos" (1689: f. 1). Entre otros momentos, podemos nombrar la Respuesta a sor Filotea donde reclama la salvedad de que su voluntad no fue escribir: "Demás, que yo nunca he escrito cosa alguna por mi voluntad, sino por ruegos y preceptos ajenos; de tal manera, que no me acuerdo haber escrito por mi gusto sino es un papelillo que llaman el Sueño" (1700: 54). El prólogo anónimo en prosa, que luego será eliminado, también replica la involuntaria producción, pero especialmente, publicación de sor Juana:

El soneto que sirve a este libro de dedicatoria le escribió a mi señora doña María Luisa Gonzaga, condesa de Paredes, marquesa de la Laguna, su gran mecenas, cuando, habiéndose de volver a España la envió a su Excelencia, pedidos por curiosidad de buen gusto y mal unidos por desestima de la madre Juana Inés unos cuadernos que amagaban a libro, y a éstos escribió el soneto, desimaginada de que sus trabajos fuesen de tanto peso, que aun hiciesen sudar en España las prensas. Y si la composición del Arco que la ciudad la encargó a las entradas en México del señor virrey marqués de la Laguna, y los villancicos a las fiestas de la Asunción y San Pedro, con otros papeles, estaban ya impresos, fue mostrar el ajeno cuidado que las venas de Indias iban mejorando de precio, no ansia de la poetisa (1689: s/n).

Son estrategias de legitimación (el descuido, la inocencia, la ausencia de voluntad creadora y publicadora) que no sólo sor Juana sostiene sobre su propia figura, sino que quienes la avalan desde los preliminares repro- 
ducen y amplían conformando una estrategia de abordaje a los futuros lectores que inician su experiencia cultural bajo la advertencia de que esos poemas y prosas son producto de un sujeto legitimado.

Carlos M. Collantes e Ignacio García Aguilar, en un artículo sobre dedicatorias femeninas (2015), sostienen que la primera autora mujer que, en vida, le dedicó sus poemas a otra mujer fue sor Juana. Este texto, entonces, sella de alguna manera una relación de amistad, pero también forma parte de un sistema literario cuyos productos tenían existencia y posiblemente eran redituables si parte de su aparato paratextual validaba la impresión a partir de la referencia directa a una persona de poder. La particularidad de las dedicatorias a benefactores/as es que el hecho de imprimir la obra con ellas no significa que fuera impresa gracias a ese benefactor. Cabe la posibilidad de que la dedicatoria fuera una apelación al favor futuro del otro y no que, como en el caso de sor Juana, condensara un vínculo de confianza iniciado casi una década atrás. Como homenaje remunerado (Genette 2001: 103), la dedicatoria da cuenta también de una relación comercial. Por un lado, sor Juana escribía lo que se conoce como "poesía de ocasión" y breves piezas teatrales como loas, saraos y bailes para cumpleaños, bautismos, nacimientos o visitas al convento de los virreyes. A cambio, sus mecenas vincularon a la poeta con otros poetas, como José Pérez de Montoro y Diego Calleja (Calvo y Colombi 2015: 87) y llevaron su obra al viejo continente.

Por otro lado, el poema que reemplaza en la reedición de Inundación castálida de 1690 (ahora llamada sencillamente Poemas...) el anónimo prólogo en prosa, y que se antepone al soneto "El hijo que la esclava ha concebido", es puramente referencial, en tanto se concibe a sí mismo como un prólogo desde sus primeros versos y a partir de la confirmación de su epígrafe, que así lo nomina. Su naturaleza paratextual, reafirmada por el hecho de no estar foliado y de reemplazar al prólogo en prosa, presenta el libro y sugiere que quien "habla" en el poema no es un yo lírico ideal, sino la misma autora que ofrece los versos a sus lectores, no a través de la mecenas sino, ahora, sin intermediarios. El prólogo como género cobra una importancia relevante en el libro impreso por constituir 
una "zona de transacción" (Genette, 2001: 8) estratégica porque establece el primer contacto entre lector y autor, mientras éste, desde el texto, pretende regular la lectura. Constituye un horizonte de espera y una guía de instrucciones en cuanto a la percepción de la obra. Al mismo tiempo, el autor del prólogo se afirma y se posiciona a través de lo que dice y anticipa las reacciones del lector. "Una de las propiedades discursivas fundamentales del prólogo consiste en unir tres tiempos (pasado, presente y futuro) en un solo acto de discurso: el acto pasado de escritura, el presente de comunicación y el futuro de la lectura" (Cayuela 1996: 224. La traducción es mía).

El poema se establece en una ambivalencia muy clara entre una escritura encargada sin voluntad ejecutora y un discurso altamente persuasivo dirigido a sus lectores y, específicamente, a su libertad interpretativa. Mientras sor Juana avanza por el romance con "la pluma trotando" (v. 48) - prosopopeya que expone una escritura planteada como fruto del tiempo ocioso-, al mismo tiempo desea controlar la interpretación del lector, a quien, en su libertad, pueden o no gustarle los poemas: "Y siempre te sirvo, pues / o te agrado, o no te agrado: / si te agrado, te diviertes; / murmuras, si no te cuadro" (v. 29-32).

Si bien sor Juana no asume la autoridad sobre su libro de poesía, bajo el argumento de que el lector no debe estimar lo que ella nunca pensó que fuera a sus manos (v. 11-12) y, en un mismo movimiento, revela que, si no fue su voluntad, tiene que haber sido de quien fomentó su impresión - la condesa de Paredes-, el reverso de esa actitud es la responsabilidad autoral de quien persuade al lector para que aprecie su trabajo. En este sentido, la ambivalencia entre la función de autoridad — quien autoriza y legitima la escritura - y la de autoría — quien se responsabiliza por ella y da fe de su propiedad (a partir de las funciones de autor de Michel Foucault) - da cuenta de una poeta que se mueve entre un sistema de signos referencial, como los vínculos coloniales entre mecenas y letrados, y el discurso literario que disfraza de libertad los pactos de poder. 


\section{UBICACIÓN(ES) DE SOR JUANA EN LAS DIAGONALES \\ DE LA CIUDAD LETRADA}

Las diagonales del damero que el ensayo de Rama tiende sobre una ciudad letrada - que no puede jamás corresponderse en sus anillos concéntricos y en sus letrados funcionales al centro de poder con la materialidad de una circulación concreta- habilitan el pasaje (la ambivalencia) entre las distintas posiciones en ese pacto de poder. El plano, aunque intenta detener el tiempo y delimitar los sentidos, se proyecta siempre hacia el futuro y hacia el pasado, y concede desplazamientos entre posiciones de sujetos no unívocos, que se mueven en la morfología de una ciudad que dispone prácticas discursivas determinadas, pero no determinantes. La ubicación -móvil- de sor Juana en este plano puede leerse en el cambio de un soneto a un romance, de una dedicatoria a un prólogo. Mientras la primera establece condiciones de producción con una responsabilidad ajena y puesta en manos del poder, el segundo asume la autoría y la carga de la publicación mientras se posiciona como una autora independiente que propone un lector ideal, libre, que pueda dejar el libro si no le gusta.

La soltura con que la poeta pasa en un año, de una edición a otra, entre autofiguraciones de autor disímiles no habla sólo de una reacción al éxito de Inundación castálida o de un poema que pudo haber llegado tarde a la publicación, sino que también es elocuente sobre la movilidad que sor Juana tenía con respecto al centro de poder que financiaba sus publicaciones. El primer volumen está dedicado a sus mecenas, en la gran mayoría de sus ediciones antiguas, pero la disposición que ese mecenas ocupa en el libro en la primera y la segunda dista de imitar círculos concéntricos e inmóviles, sin disidencias ni pasajes, sino, más bien, ilustra la apertura a una inestabilidad que el ensayo de Rama permite pensar y que sor Juana aprovecha.

Ampliar el ensayo de Rama es comprender la potencialidad intrínseca de su escritura y de sus ideas. Su estructura y su trama textual proponen diagonales y pasajes que sugieren sutilmente aquello que las críticas más frecuentes (su rigidez y su atemporalidad) reclaman. A pesar de - y gracias 
a- estas críticas, La ciudad letrada sigue siendo un texto fundamental para comprender los vínculos entre urbanidad, escritura y poder en América Latina, especialmente en la colonia. El ejemplo que tomamos en estos dos poemas leídos lado a lado propone una lectura alternativa desde la ciudad letrada, aprovechando sus posibilidades sin dejar de tener en cuenta sus limitaciones. El lugar de sor Juana en el ensayo de Ángel Rama ocupa un espacio pequeño, pero fundamental, ya que su inclusión permite otras lecturas descentradas, diagonales, desviadas del concepto que le da título y, por qué no, del libro en su totalidad.

BibLIOGRAFíA

ADORNo, Rolena. "La ciudad letrada y los discursos coloniales". Hispamérica XVI. 48 (1987): 3-24.

Aguilar, GonZalo. "Las costuras de la letra". Prismas 10 (2006): 173-176.

ALATORRE, ANTONIO. "Un tema fecundo, las encontradas correspondencias". Nueva Revista de Filología Hispánica, LI. 1 (2003): 81-146.

BEVERLY, JOHN. Subalternity and Representation in Cultural Theory. Durham: Duke uP, 1999.

BuXÓ, José PASCuAL. "Sor Juana Inés de la Cruz: amor y cortesanía". Colonial Latin American Review 4. 2 (1995): 85-100.

Calvo, Hortensia y Beatriz Colombi. Cartas de lysi. La mecenas de sor Juana Inés de la Cruz en correspondencia inédita. Madrid/Frankfurt/México: Iberoamericana/Vervuert/Bonilla, 2015.

Cayuela, Anne. Le paratexte au Siècle d'Or. Libraire Droz: Ginebra, 1996. Collantes Sánchez, Carlos M. e Ignacio García Aguilar. "Dedicatorias femeninas en la poesía impresa del bajo barroco". Criticón 125 (2015): 49-54.

Colombi, BeATriz. "Una gesta antiépica”. Prismas 10 (2006): 181-183.

CruZ, SOR JuAna InÉS DE LA. Inundación Castálida de la Única Poetisa, Musa Décima, sóror Juana Inés de la Cruz, religiosa profesa en el monasterio de San Gerónimo de la imperial ciudad de México, 
que en varios metros, idiomas y estilos, fertiliza varios asuntos con elegantes, sutiles, claros, ingeniosos, útiles versos, para enseñanza, recreo y admiración. Madrid: Juan García Infanzón, 1689.

Poemas de la Única Poetisa Americana, Musa Décima, sóror Juana Inés de la Cruz, religiosa profesa en el monasterio de San Gerónimo de la imperial ciudad de México, que en varios metros, idiomas y estilos, fertiliza varios asuntos con elegantes, sutiles, claros, ingeniosos, útiles versos, para enseñanza, recreo y admiración. Madrid: Juan García Infanzón, 1690.

. Fama y obras pósthumas del Fénix de México, Décima Musa, Poetisa Americana, sor Juana Inés de la Cruz, religiosa profesa en el convento de San Gerónimo de la imperial ciudad de México. Madrid: Imprenta de Manuel Ruiz de Murga, 1700.

DERRIDA, JaCQues. De la gramatología. Buenos Aires: Siglo XXI, 1986.

EGIDO, Aurora, "La hidra bocal: sobre la poética del barroco". Edad de Oro VI (1987): 79-183.

FARRÉ, JUDITH. "Espectáculos parateatrales en las entradas de virreyes en la Nueva España: el caso del Conde de Paredes (1680)". Bulletin of the Comediantes 58. 1 (2006): 73-87.

FERnÁndeZ BraVo, Álvaro. "La provocación de La ciudad letrada". Prismas 10 (2006): 185-189.

FORT, MARÍA Rosa. "Juego de voces: los sonetos de amor y discreción de Sor Juana Inés de la Cruz". Revista de Crítica Literaria Latinoamericana XVII. 34 (1991): 33-45.

FouCAult, Michel. "¿Qué es un autor?". Trad. Corina Yturbe. Dialéctica. Revista de la Escuela de Filosofía y Letras. 16 [1969] (1984): 51-82. - Las palabras y las cosas. Buenos Aires: Siglo XXI, 2002.

GENETTE, GERARD. Umbrales. México: Siglo XXI, 2001.

GLANTZ, MARGO. "El jeroglífico del sentimiento: la poesía amorosa de sor Juana". Obras reunidas I. Ensayos sobre la literatura colonial. MéxiCO: FCE, 1995. 
MARISCAL HAY, BEATRIZ. "Una 'Muger ignorante': sor Juana, interlocutora de virreyes". Sara Poot Herrera (ed.). Y diversa de mí misma entre vuestras plumas ando. México: El Colegio de México, 1993.

MÉNDEZ, MA. ÁGUEDA. "La ciudad como ámbito de la cortesanía. Sor Juana y la ceremonia ritual". Anthropos 243 (2016): 37-52.

MORAÑA, MABEL. "De La ciudad letrada al imaginario nacionalista: contribuciones de Ángel Rama a la invención de América". Beatriz González y Javier Lasarte et al. (comps.). Esplendores y miserias del siglo XIX. Cultura y sociedad en América Latina. Caracas: Monte Ávila Editores Latinoamericana, 1995. 166-173. (ed.). Ángel Rama y los estudios latinoamericanos. Pittsburgh: Instituto Internacional de Literatura Iberoamericana, 1997.

NAVASCUÉS, JAVIER DE. "Lo que cantó sor Juana a los reyes de España: las loas en celebración de los cumpleaños reales". José María Ferri y José Carlos Rovira (eds.). Parnaso de dos mundos. De literatura española e bispanoamericana del Siglo de Oro. Madrid: Iberoamericana, 2010.

PAZ, OCTAVIO. Sor Juana Inés de la Cruz o las trampas de la fe. Buenos Aires: Fondo Cultura Económica, [1982] 1992.

Picón SALAS, Mariano. De la Conquista a la Independencia. México: FCE, 1969.

POOT HeRRERA, SARA. "La poesía inicial de sor Juana ya en el "virreinato de filigrana". Antbropos 243 (2016): 17-35.

RAMA, ÁNGEL. La ciudad letrada. Montevideo: Arca, 1998.

Ramos, Julio. Desencuentros de la modernidad en América Latina. Literatura y politica en el siglo XIX. Buenos Aires: FCE [1989] 2003.

RODILla LEÓN, MARíA JosÉ. "Aquestas son de México las señas". La capital de la Nueva España según los cronistas, poetas y viajeros (siglos XVI al XVIII). México: Iberoamericana/Vervuert/UAM, 2014.

Ruiz, Facundo. "Prólogo". Sor Juana Inés de la Cruz. Nocturna, mas no funesta. Poesía y cartas. Buenos Aires: Corregidor, 2014.

SabAT De Rivers, Georgina. "Veintiún sonetos de sor Juana y su casuística del amor". Sor Juana y su mundo. Una mirada actual. México: Universidad del Claustro de Sor Juana, 1995. 
SigüEnZa y GÓngora, Carlos. Seis obras. Prólogo de Irving A. Leonard. Caracas: Biblioteca Ayacucho, 1984.

SOLANO, FRANCISCO DE (ed.). Normas y leyes de la ciudad hispanoamericana: 1492-1600. Madrid: Csic, 1996.

Todorov, Tzvetan. La conquista de América. El problema del otro. México: Siglo XXI, 1998.

ZANETTI, SUSANA. "El letrado y la plebe: alboroto y motín de México de 1692 de C. de Sigüenza y Góngora”. Melchora Romanos (coord.). Lecturas críticas de textos hispánicos. Estudios de literatura española. Siglo de Oro. vol. 2. Buenos Aires: Eudeba, 2000.

Zavala, IRIS. "Burlas al amor". Nueva Revista de Filología Hispánica 29. 2 (1980): 367-403. 